\title{
Power, Death and Love: A Trilogy for Entertainment
}

\author{
Ben Salem and Matthias Rauterberg \\ Department of Industrial Design, Technische Universiteit Eindhoven, The Netherlands \\ \{b.i.salem, g.w.m.rauterberg\}@tue.nl
}

\begin{abstract}
In this paper we review the latest understandings about what emotions are and their roles in perception, cognition and action in the context of entertainment computing. We highlight the key influence emotions have in the perception of our surrounding world, as well as in the initiation of action. Further to this we propose a model for emotions and demonstrate how it could be used for entertainment computing. We then present a review of emotion based toys and show our own development in this area. We conclude our paper with a discussion on how entertainment systems would gain from a better and more comprehensive understanding of emotions.
\end{abstract}

Keywords: Emotion, power death love trilogy, empathy, interactive toy.

\section{Introduction}

There have been numerous definitions given to the concept of emotions. It would go beyond the scope of this paper to give a comprehensive and complete survey of the various definitions given to emotions in a wide variety of sciences and philosophical schools. We will instead focus on those definitions that help us understand emotions from the perspective of entertainment. To understand emotions, we have relied on current developments in neuroscience, psychology, Human-Computer interaction and Artificial Intelligence. More specifically, we have looked at what have emotions been described as and what have they been related with.

Emotions have been associates with decision-making processes [1], and with regulation of behaviour [2]. Emotions help us keep out of harm's way effectively and efficiently. As an initial reaction to unknown experiences emotions ensure we are not hapless and indecisive when a choice or a decision need to be made. Even in the case of contradicting and incomplete information availability. Emotions are an essential part of our cognitive and behavioural capabilities [3], and play a continuous role in defining who we are as individuals. Some even advocate that no cognitive process is possible without emotions [4]. As well as that emotions should play an important part in the field of Human-Computer Interaction [5].

Emotions have social functions [6], and society has an influence on our emotions [7]. Emotions also play a role in our perception of reality down to the perception of our own body generated signals such as pain. Such influence is due to changing of the focus of our attention [8] [9]. Emotions also require some processing and regulation. It is a mechanism to avoid that an emotional experiences becomes overwhelming and

F. Kishino et al. (Eds.): ICEC 2005, LNCS 3711, pp. 279-290, 2005.

(C) IFIP International Federation for Information Processing 2005 
thus prevents other experiences and processes to proceed without hindrance [10]. The emotional regulation is performed continuously and in a way to ensure that we are not overwhelmed with emotions. Both emotional processing and regulation are complex mechanisms that are not always effective. Emotional avoidance for example can result in an increased in self-generated emotions leading to a self-perpetuating and amplifying loop and defeat the purpose of such an avoidance [11]. In other words, we become victim of a panic attack [12].

In this paper we propose to investigate how a better knowledge and understanding of emotions could help develop better entertainment systems. We define entertainment systems as those that deliver an attention holding diversion. In effect, entertainment systems grab your attention away from your daily routine. Because emotions are known to affect attention [8] [9], the link is therefore strong between emotions and entertainment. Traditionally, there has been emphasis on the entertainer to provide a trigger for an emotional response from the user/audience. This is particularly the case with historical entertainments such as performing and fine arts. More recent entertainment systems based on information technologies have permitted the emergence of emphasis on the media used to carry/render the emotions. In essence a video game or a multimedia system will explore a combination of modalities and medias to deliver an effective entertainment. Latest entertainment, due to the emergence of the Internet and other networks have given room for the sharing of the experience and of the emotions between users.

Entertainment systems have evolved into three major groupings: (1) The explicit rendering, and the asymmetric (mainly performers to user) flow of emotions (e.g. Paintings); (2) the media and mode rich rendering, and the symmetric (performer to and from user) flow of emotions (e.g. multimedia games); (3) the realism, and the triangular (performer to and from users and between users) flow of emotions (e.g. online games). While some forms of entertainment will directly express a variety of emotions, others will abstract emotions into music, colours etc. Emotions are experienced when using a form of entertainment and in some cases the emotions are also shared with other users or with the provider of the service. What is of particular relevance in this grouping is that for human to human communication to occurs and thus a possible dynamic exchange of emotions there is a need for either one of two possibilities: (1) The performer of the entertainment is human and he is connected to the audience (e.g. theatre); (2) there is a connection between users (e.g. Internet games or audience in a street theatre). As we are interested in rich dynamic emotional exchanges we have thereafter to ensure that it is the case that in our system either one of these two possibilities occurs.

\section{Emotions}

\subsection{Dimension of Emotional Experiences}

Emotions are a combination of physiological, psychological and physical experiences. They include a combination of motor, sensory, autonomic, cognitive and affective experiences. A Sensory experience is related to the emotions that we perceive thanks to our perception. An example is the perception of sadness in a facial expression. 
Motor experience is the physical changes our body goes through when experiencing an emotion, e.g. physical withdrawal when scared. Cognitive experience is related to our assessment of the emotion we are experiencing and the conscious thinking about it (see also the discussion in [23]). In essence it is the conscious experience of our emotions. The affective part is about how we project an emotion onto the object that has provoked the experience. So we project happiness towards a friend and fear towards a gun. The autonomic experience is about the autonomic response we have of our emotions. Face blushing, increased heart beat and sweating are good examples.

\subsection{Emotional Concerns: A Trilogy}

Although there has been consensus in accepting that emotions are directed towards an object [13]. We advocate a more encompassing description of emotions as requiring several components rather than an object. The experience of emotions is a phenomenon that takes place as the result of exposure to a combination of up to three components: a situation, an environment or an object. An example would be having a conversation, in a hot office while holding a stress ball. The conversation could be at the origin of some emotions, the temperature of the office will induce stress and negative emotions while the stress ball could help you gain some relief. It is a rather simplistic portray of emotions but it does include the three possible origins for an emotional experience. Either of these components or a combination thereof will be of relevance to the individual. Such relevance is determined by the influence, the significance, the importance and the effect(s) the exposure will have on a person. More specifically, the resulting changes on his needs, requirements and desires. The needs are the essential necessities of a person, such as breathing and eating, the requirements are necessary elements to fulfil a function or a task, while the desires are related to a person goals, concerns, beliefs and drives. It is also important to investigate what would be capable of provoking an emotional response. As not all events will have an influence on our emotions. How could one draw some general rules which could be used to determine the influence an event would have on emotions.

The brain could be described as a pleasure seeking system that has sophisticated circuitry to generate and appreciate pleasurable stimulis (see [14]). It does make sense to seek to establish what does trigger pleasurable stimulis. Beside cognitive processes the brain is also home to affective processes that are the seat of our emotional experiences. Current knowledge of functional neuro-anatomy of the brain indicate that sensory imputs and their assessment play a major triggering role in the emotions that we experience (see for example [15]). Furthermore, the assessment of sensory inputs is generaly performed in line with personal concerns. These concerns can be personal, or universal, general or specific (i.e. confort, well being, social relations). Our interest in these emotional concerns lies in those that are universal, we call them major concerns. We advocate that these majore concerns are generally related to: (1) power (e.g. hierarchy, competition, and submission); (2) death (e.g. violence, health, and self preservation), and (3) love (e.g. friendship, hatered, and lust). What is noticeable is that our lives are rich with combinations of these major concerns. Such combinations are not necessarily balanced between the three. In fact without wanting to advocate such a cynical view it seems that power is the ultimate concern with death, and love the most effective means used to overcome it. Our trilogy of 
emotional concerns has been established by looking at several elements of human history, culture and religions e.g. remarkable events, lasting buildings and work of art that have a certain historical or cultural value ${ }^{1}$. Indeed historical events, are all reported within the perspective of one of the three concerns (king legends, wars and love stories). It is cross cultural and cross centuries (Maharabata 5BC - 2AD, Shakespeare works such as Macbeth 1605-1606, and Romeo and Juliet 1594-1595). Even contemporary media relate to these three concerns (see figure 1).
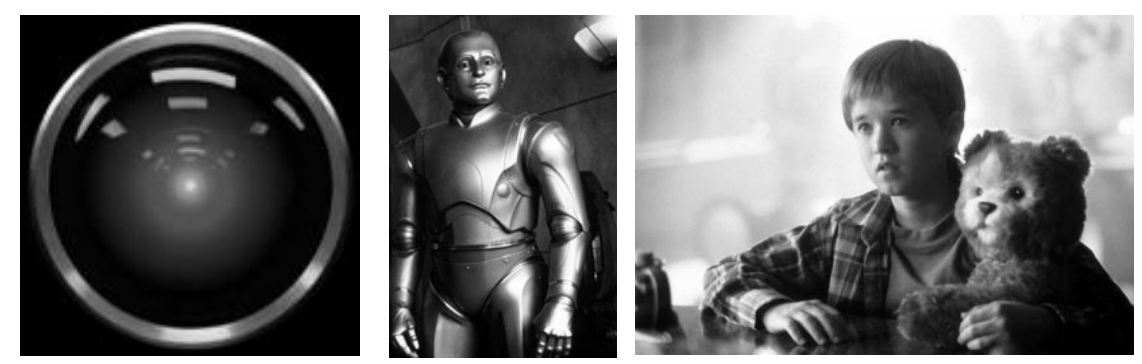

Fig. 1. Power, Death and Love as human characteristics. From left to right: In "2001", HAL takes over power as he considers humans not capable of handling the mission properly [16]. In "The Bicentennial Man", Andrew Martin the robot seeks to die to become human [17]. While in "AI" David the child robot is seeking maternal love [18].

Furthermore, there are medical evidences that sustain our proposal of emotion concerns. LSD and other hallucinogens help people feel like empowerment and the presence of powerfull elements as well as out-of-body experiences. A similar experience of life-after-death is also reported from patiens with brains that are under anoxic (low oxygen) conditions [19]. Patients suffering from Complex Partial Seizures have reported hypersexuality and hyposexuality [20]. Epilectic subjects also report on the feeling of an overwhelmingly powerful being and some have shown hypersexuality [19]. Finally looking at folk culture and traditions, hypnotic states and states of trance have been described as means to reach higher self-control (meditation), after-death (medium) and higher level of sexual pleasures (orgasm prolongation exercises).

\subsection{Fundamental Emotions}

According to functional neuroanatomy of the bain, there appear to be five emotions that we all share as they have dedicated parts of the brain [21]. We call these fundamental emotions. The five fundamental emotions (FEm) are: (1) anger, (2) disgust, (3) fear, (4) happiness, and (5) sadness. These five FEms have a substantially more significant role that the reminder of emotions which we experience. This is due to the dedicated brain circuit for each one. As a general rule the five FEms are essential for our well being and safety. They ensure that we are equipped to deal with a range of situations (dangerous, safe, beneficial etc.). They take us out of harm's way

\footnotetext{
${ }^{1}$ The original idea of this trilogy was provided by Marcel Reich-Ranitzky.
} 
by providing a motivation for actions either avoidance (disgust), escape (fear), introspection (sadness). FEms provide us with basic social skills attraction (happiness) and rejection (anger) of our peers. Other emotions as we experience them are social and cultural constructs. We learn to understand the emotional experience as more than the FEms, due to the context where it occurs. So for example anger associated with an individual will become disliking [23]. In our opinion, highlighting these emotions could be beneficial for the development of more effective entertainment systems.

\section{A Role for Emotions}

Emotions were considered as the mechanism necessary to initiate a wide range of actions not deemed essential. Blushing or smiling are directly initiated by our emotional experience. While keeping the balance, breathing and others actions are not initiated by emotions, although they can be modified by them. Until recently preventing one's emotions and controlling one's emotional reactions was deemed necessary when making decisions and choices. The argument was that one should think rationally and logically rather than impulsively and emotionally.

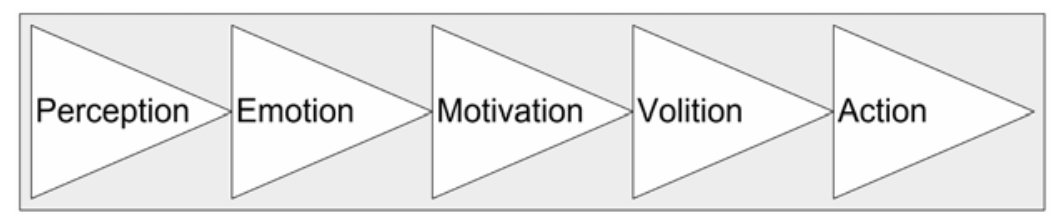

Fig. 2. The conventional understanding of emotions is that we first perceive something, we then experience an emotion related to that event. Our emotion will then motivate us to action. Thus follow volition and then action.

From emotions we draw motivation and action (see figure 2). Emotions in this model are the result of perception, which could be misguided. Therefore, it was accepted practice to ignore, inhibit and control one's emotions and not to use them as a decision mechanism. Until recently, emotions were not even included in cognitive processes. A good example is the unlikely emotionless character of Mr Spock in the star trek series.

However, looking at the latest development in funcional neuroanatomy of the human brain. Emotions can be considered as resulting from an input stimuli. Such an input is assessed by the brain emotional engine as described in figure 3. The emotional input is processed and yields an emotional response or a lack thereof. In all cases emotional responses are a result of the assessment of emotional input in terms of the positive effect such input could have in any single or any combination of emotional dimensions as described in section 2.1. Thereafter is it important to high light two key facts about emotions. First emotions are rendered within the perspective of the self, and second emotion have a hedonistic dimension in that there is a positive 
correlation between the reward associated with an emotional input and the kind of emotional response rendered as a result of the same emotional input.

Another relevant fact, within entertainment computing is the time dependence of emotions (see figure 4). We have established a timeline of emotions ranging from the short timed emotional response such as laughter to a much longer emotional response such as moods and trait. Further down the line personality and characters are emerging as part of one's emotional profile over a period of time that spans years.

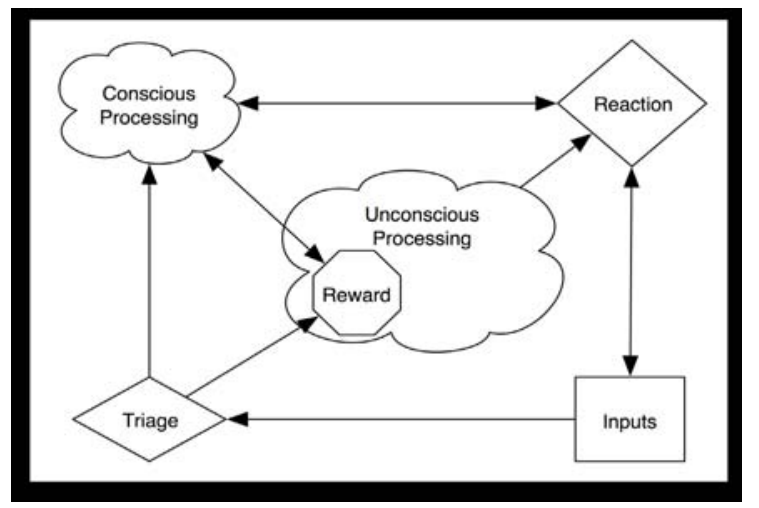

Fig. 3. A simplified brain pathway for emotions as extrapolated from [21] [15]. What is interesting and relevant within the context of entertainment computing is that the emotional reaction feeds back into the input channels of our senses and is thus again part of an emotional reaction. Letting such a loop loose, leads to overwhelming emotions and panic.

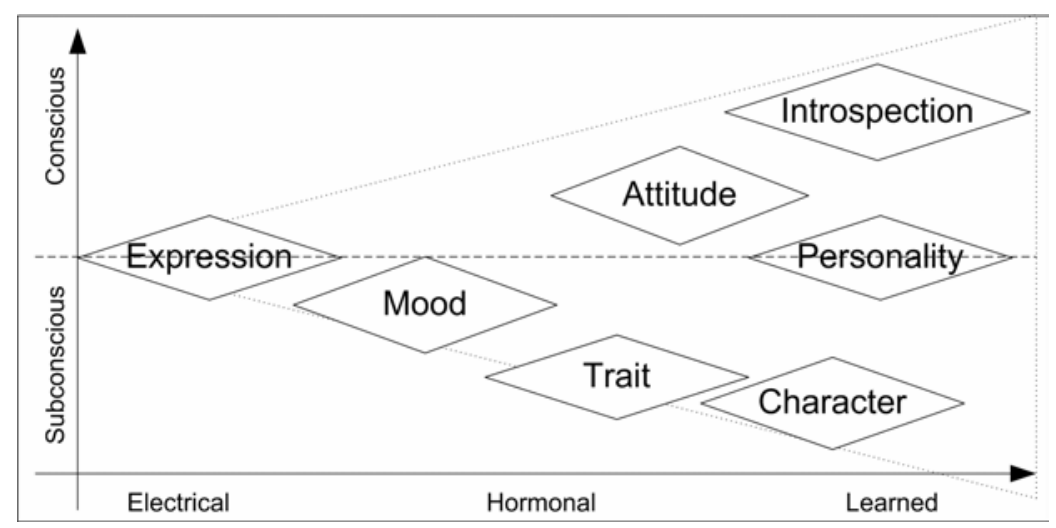

Fig. 4. Emotions have a time dependence that is often overlooked. Short time span of seconds is generally related to the electrical activity of the neurons and result in the experience and expression of emotions. Further time is generally required for hormonal effects which results in a change of mood and trait one can be known as having. With a longer time span, attitude, character and personality start to emerge as qualities of an individual. 


\subsection{Emotions and Pleasures}

Emotions can also be defined as the hedonistic assessment of our sensory inputs. The inputs are evaluated in terms of their pleasure value. The hedonist value, a perceptual event may have, is related to the amount of pleasure one is expected to experience. As a result we use emotions to assess how pleasurable or pleasure inducing a perceptive event can be. This result in a positive to negative assessment of an emotional experience, also called valence [24]. The emotions hedonistic value is linked to the expectations within the context of the emotional experience and the expressive value and consequences as part of communication. In general we build expectations whatever the context we are in, not only about what should happen but also about our own behaviour. As a result events that do not fall within the expectations will yield emotional responses that might be difficult to manage and with the tendency of being classified as negative. Similarly the expressive value and consequence of the expression of an emotion play a role in the kind of expressions one will be experiencing. In other words people are more likely to experience emotions as they are expected to, than otherwise. Socio-cultural habits and rules are established during our life to help construct a comprehensive set of rules regarding the acceptability of emotions. This is another relevant fact when designing entertainment systems. In short it is better to integrate emotion rendering that are known and familiar to the user. This would yield a clearer if not stronger emotional perception.

\section{Emotions and Entertainment}

From the pervious sections we have seen that emotions are a rather complex concept. Furthermore to add to the problems there are no clear rules on how to provoke an emotion. One can rely on centuries of entertainment to see how emotions have been abstracted, rendered and perceived. Theatre has shown how successfully a wide spectrum of emotions can be used. However with the advent of entertainment computing, there has been increased pressure to explore the wide spectrum of emotions rather than to focus on what current entertainment computing has delivered. We know that there are five fundamental emotions (FEms) (disgust, fear, sadness, happiness and anger). We advocate that entertainment computing could gain from exploiting these five emotions as the basis for the service provided. We thus combine these emotions with the three emotional concerns of mankind. We list next some of the current developments and what systems exist in this matrix-like arrangement between the three concerns and the five FEms. As it would otherwise be a too large task, we will focus in the next sections on games, toys and robots to illustrate our point about emotions and entertainment.

\subsection{Death and Love Entertainment}

Emphatic electronic toys are a recent development (1998). Furby is a good example, it has been a very successful toy selling at more than 40 millions units [25]. A new generation is currently being developed: "The emotional response of the new FURBY creature is one of the most noticeable changes from the original. EMOTO-TRONICS allows the FURBY creature to react based on how a child interacts with it" [idem]. 
The attribution of life-like characters to Furby is such that there are several websites related to autopsies of the toy (e.g. [26]). Other developments in this area include the micro-pets from TOMY [27] and the new generation Tamagotchi [28]. With empathic toy the issue of positive, altruistic behaviour (caring and loving) as part of entertainment has been addressed. Until then no entertainment computing systems was related to an altruistic attitude towards entertainment. Rather many systems relied on an egoistic attitude towards entertainment. One has to go to the world of basic toys such as dolls (Barbies and notably babies-like dolls) to find such equivalence to today empathic electronic toys (see figure 5). What is notable, is the combination of death and love for the Tamagotchi and Furby!
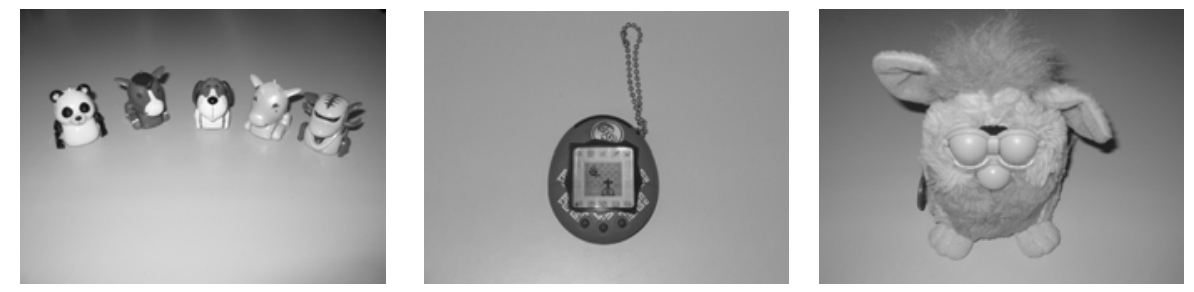

Fig. 5. Empathic toys: Micro-Pets (left) from TOMY, Tamagotchi (middle) from BANDAI, and Furby (right) from Hasbro. For each of these toys the owner is required to "nurture" them, play with them and attend to their needs. In essence you need to care for them. The FEms involved are happiness, sadness and to a lesser extent anger.

\subsection{Power and Death Entertainment}

Most current games of first person shouting are combining power and death (e.g., figure 6). The game objectives are generally about taking over control of some country, city, or base and to kill as many of the enemy as possible. In effect, death (of opponents) is used as a mean to reach power.
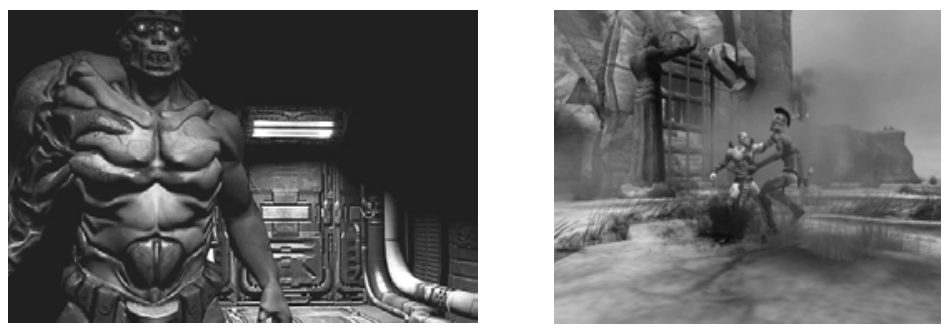

Fig. 6. Doom (left) [29] and God of war (right) [30] games. Highly popular computer games are related to death and power. The FEms involved are fear, anger and disgust.

\subsection{Power and Love Entertainment}

This category has mostly been focused on adult explicit games (e.g. see figure 7). These games have a common scenario in that the player is in control of the script and what actions, generally of sexual nature will the character perform. Lust is used to achieve power over the characters portrayed. 

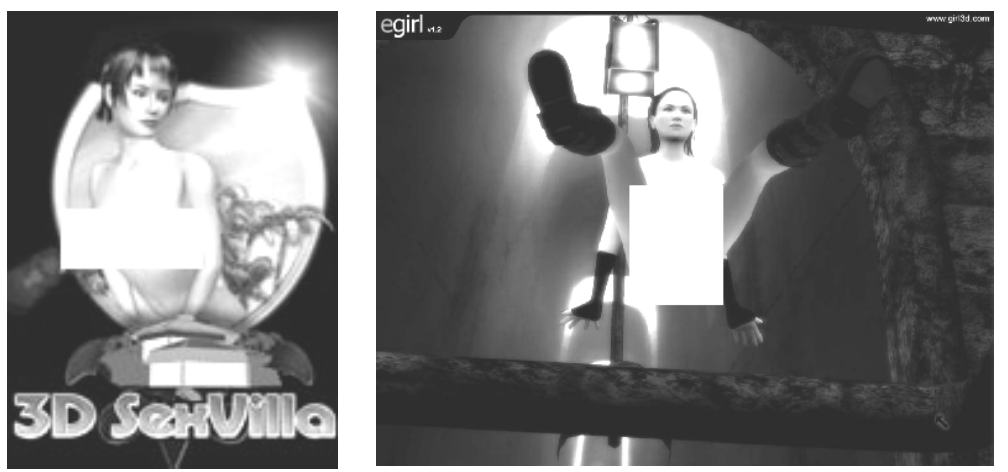

Fig. 7. 3D SexVilla (left) [31] and egirl (right) [32] games. In 3D SexVilla players are in control of what females will do in terms of sexual activities. Similarly with egirl although your control goes to a further extent.

\subsection{Love and Death Entertainment}

Therapeutic robots have been developed to provide for patient support for their emotional needs. In essence patient use the robots to project love and care and in return feel as if involved with a loving pet. Positive results have been reported, the robots do have purpose in improving the patient condition. Similarly the idea of "resurrecting" your dead pet is a form of death and love entertainment. In the example presented (see figure 8), it is no less than a zombie cat that is proposed (i.e. a pet robot covered with the actual skin of your beloved cat).
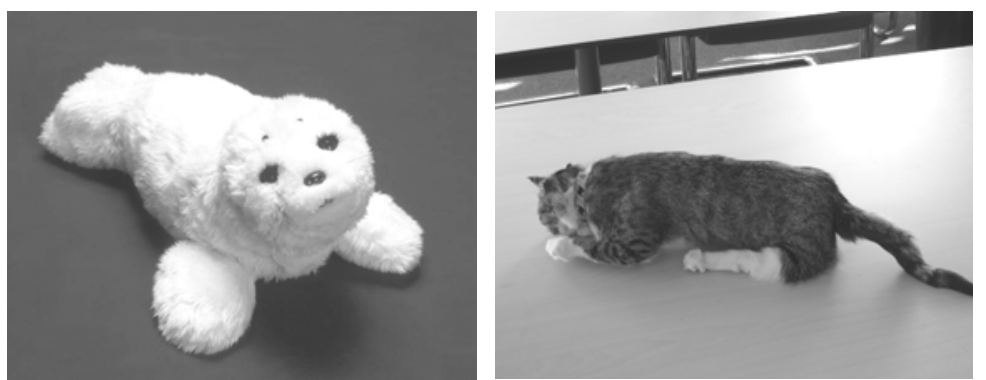

Fig. 8. Therapeutic robot Paro (left) and the "zombie cat" (right). Paro helps you recover from your illness, using love that you feel for it to help you recover from illness [33]. The zombie cat was developed as a pet robot that acts as sleeping packaged in the skin of a beloved cat. Thus creating a zombie combines death and love [34].

\section{Power and Love Entertainment: The Mollycoddle Robots}

In the perspective of the ideas presented in this paper and the review of current entertainment systems, we have launched the mollycoddle project. In this project, the key issues to be addressed were: (1) Rendering of emotion through postures and movements, (2) Effective human perception of the emotions expressed by the robot, (3) 
Clear rules of engagement and social rules used by the human and the robot, (4) As natural as possible interaction between the user and the robot, (5) Real-time performance by the robot. The robot was designed for 8 to 12 years old girls. Our students were asked to investigate the main interests, needs, requirements and desires of this population of users. The students were requested to develop a toy that has some expressive functions and that must be held to be used. We then encouraged two different directions for two groups, one was power toy, where by the mollycoddle should be used for power projection. The second direction was love: the mollycoddle should be used to express love. Both toys have a soft body with embedded electronic circuitry.

\subsection{Power Toy: The Cuddle}

In the case of cuddle, power is associated with fights with friends. Initial user tests have demonstrated the popularity of Cuddle (see figure 9). Accelerometers detect actions and control the playback of cartoon animals and characters recordings.
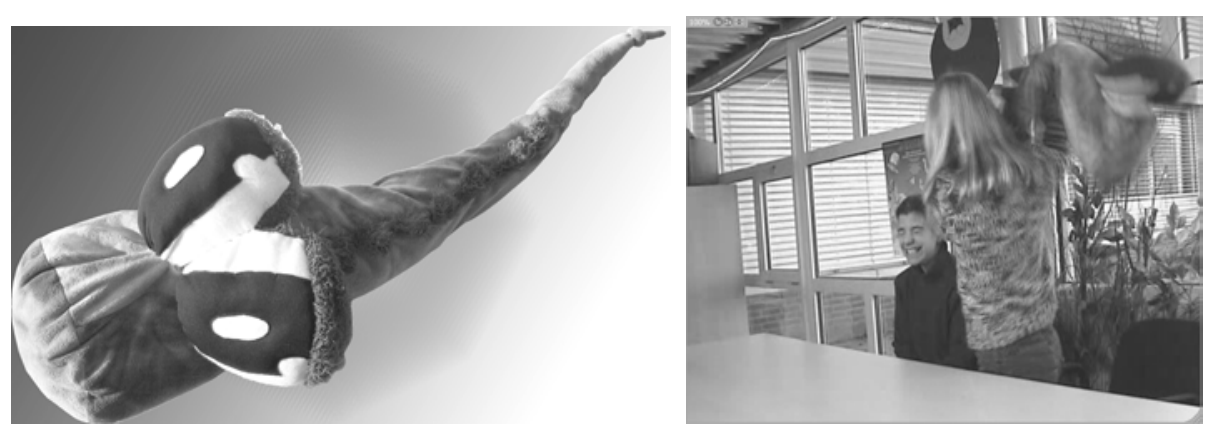

Fig. 9. A mollycoddle toy emphasising power: Cuddle (left). Such a toy was designed to hit your friend. Cuddle can be used in "pillow fights" (right).

\subsection{Love Toy: The Miko}

The core of Miko is a modified hard-disk drive used to translate sounds into vibrations (see figure 10). Heartbeats are thus generated and can be felt when handling
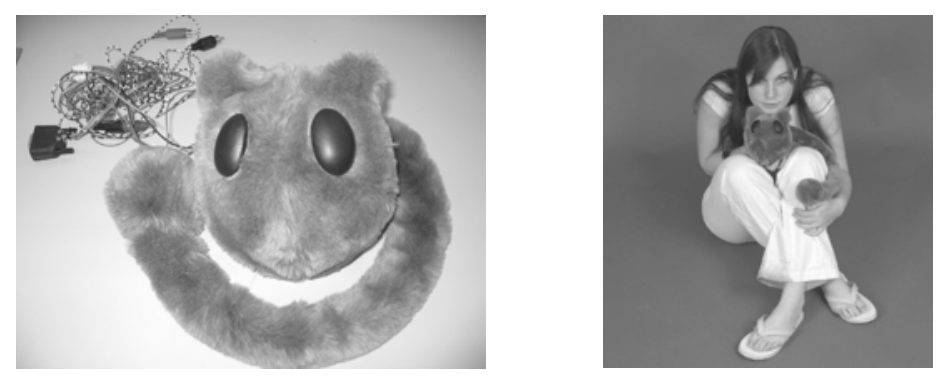

Fig. 10. A mollycoddle toy emphasising love: Miko (left). Such a toy was designed with emotion rendering functions. In the case of Miko sounds are translated into vibrations. These vibrations can only be felt if the toy is tightly held (right). 
the toy. The tail of Miko is also equipped with a small vibrating engine. As a result one can feel and slightly hear a buzzing sound coming from the tail.

\section{Conclusion}

Entertainment computing has emerged as an alternative to conventional entertainment. It is an alternative rather than a continuation, because as we have discussed it here there is a clear potential for such entertainment to go beyond the usual understanding of what is entertainment. Understanding what emotions are and how to use such understanding in the development of novel entertainment systems is part of objectives of this paper. Furthermore we hope that this attempt at understanding emotions within this context should initiate further developments in the way entertainment is delivered. While most entertainment has been passive over the past, entertainment computing gives us the opportunity of a more user active involvement. Combining this with a refined model of emotions and their rendering should yield more exhilarating entertainment. We hope to have demonstrated that our proposed trilogy can be successfully applied in the design of a new generation of entertainment robot toys. One of the difficulty we have met is creating toys that are truly addressing one and only one of our major concerns. Future work would be in developing systems that embody a combination of these concerns and ultimately the whole trilogy. Finally we hope to have open a debate in the entertainment community about what direction could be taken in the development of new systems.

Acknowledgements. The authors wish to thank our students for their work on the Miko project. The micro-pets pictured were kindly donated by TOMY France.

\section{References}

All URLs listed were last visited March 2005.

[1] Bechara, A.: The role of emotion in decision-making: Evidence from neurological patients with orbitofrontal damage. Brain and Cognition (2004), 55, 30-40

[2] Toates F.: Cognition, motivation, emotion and action: a dynamic and vulnerable interdependence. Applied Animal Behaviour Science (2004), 86, 173-204

[3] Gross, J.J. Emotion and emotion regulation. In L.A. Pervin \& O.P. John, (Eds.), Handbook of personality: Theory and research. Guilford, New York, NY, USA (1999) 525-552

[4] Pickard, R.W.: Does HAL cry digital tears? Emotions and computers. In D.G. Stork (Ed.), Hal's legacy: 2001's Computer as Dream and Reality. MIT Press, Cambridge, MA, USA (1997) 279-303

[5] Brave, S., Nass, C.: Emotion in Human-Computer Interaction. In J.A. Jacko \& A. Sears, (Eds.), The Human-Computer Interaction Handbook, Lawrence Erlbaum, Mahwah, NJ, USA, (2003) 81-96

[6] Parrott, W.G., Smith, R.H.: Distinguishing the experiences of envy and jealousy. Journal of Personality \& Social Psychology (1993), 64(6), 906-920

[7] Fridlund, A. J.: Sociality of solitary smiling: Potentiation by an implicit audience. Journal of Personality \& Social Psychology (1991), 60(2), 229-240

[8] de Wied, M. \& Verbaten, M.N. Affective pictures processing, attention, and pain tolerance. Pain, 90, Feb 2001, 163-172 
[9] Ohman, A., Flykt, A., Esteves, F.: Emotions drives attention: detecting the snake in the grass. Journal of Experimental Psychology General (2001), 130, 466-478

[10] Rachman S.: Emotional processing with special reference to post-traumatic stress disorder. International Review of Psychiatry (2001), 13( 3), 164-171

[11] Hayes, S.C., Strosahl, K.D., Wilson, K.G. Acceptance and commitment therapy. An experimental approach to behavior change. The Guilford Press, New York, NY, USA (1999)

[12] Baker, R., Holloway, J., Thomas, P.W., Thomas, S., Owens, M.: Emotional processing and panic, Behaviour Research and Therapy (2004), 42, 1271-1287

[13] Frijda, N.H. Varieties of affect: Emotions and episodes, moods, and sentiments. In P. Ekman \& R.J. Davidson (Eds.), The nature of emotion (1994), Oxford University Press New York, NY, USA, 59-67

[14] Berridge, K.C.: Pleasures of the Brain. Brain and Cognition (2003), 52, 106-128.

[15] Nolte, J. (2002): The Human Brain - An Introduction to Its functional Anatomy. St Louis, MI, USA, Mosby.

[16] Kubrick, S., Clarke, A.C.: 2001: A Space Odyseey, (1968)

[17] Columbus, C., Asimov, I.: The Bicentennial Man, (1999)

[18] Spielberg, S., Kubrick, S.: AI, (2001)

[19] Smith Churchland, P. (2002), Brain-Wise: Studies in Neurophilosophy. Cambridge, MA, USA, Bradford Book, MIT Press

[20] Cytowic, R.E. (1996), The neurological side of neuropsychology. Cambridge, MA, USA, MIT Press

[21] Luan Phan, K., Wager, T., Taylor, S.F., Liberzon, I. Functional Neuroanatomy of Emotion: A meta-analysis of emotion activation studies in PET and fMRI. NeuroImage (2002), 16, 331-348

[22] Rolls, T.E. (1999): The Brain and Emotion. Oxford, England, Oxford University Press.

[23] Libet, B.: Do we have free will? Journal of Consciousness Studies (1999), 6, 8-9 47-57

[24] Rusell, J.A.: A circumplex model of affect. Journal of Personality and Social Psychology (1980), 36, 1161-1178

[25] See: http://www.hasbro.com/media/pl/page.release/dn/default.cfm?release=277

[26] See: http://www.phobe.com/furby/

[27] See: http://www.tomy.fr/

[28] See: http://www.tamagotchi.com/

[29] See: http://www.doom3.com/

[30] See: http://www.the-nextlevel.com/previews/ps2/god-of-war/

[31] See: http://www.3d-sexgames.com/

[32] See: http://www.girl3d.com/

[33] See: http://www.aist.go.jp/aist_e/aist_today/2003_09/robot_01.html

[34] Klarenbeek, D. invented the "zombie cat". In personal conversation with the authors 